\title{
IMPLEMENTATION OF CONSTRUCTION SAFETY IN REINFORCED CONCRETE CONSTRUCTIONS EXECUTED BY COMPANIES WITH MODERATE VOLUME
}

\author{
W.W.Al-Buzz ${ }^{1}$, M. M. Mostafa ${ }^{2}$ \\ ${ }^{1}$ Civil engineering Dept. Taif University, Al-Hawih, P.O.Box 888, Z.C.21974, Taif Saudi Arabia \\ ${ }^{2}$ Civil engineering Dept. Taif University, Al-Hawih, P.O.Box 888, Z.C.21974, Taif Saudi Arabia
}

\begin{abstract}
In order to achieve the purpose of this research, a special questionnaire were designed to fulfill the task of this research, exemplified the subject of safety where what is supposed to be present in the workplace and means of prevention that contribute to raising the safety and industrial security degree rate to the highest level, based on the regulations and safety standards followed in Saudi Arabia, compared to what is the case they have both in field sites or within constructions, the questionnaire has been distributed in some construction projects distributed in different places located in Kingdom of Saudi Arabia, and has been narrowed in the building and construction sector category, then study what came in its provisions, for the purpose of the process of analyzing, and to study the causes of accidents, in order to achieve the aim of this research.
\end{abstract}

Keywords - Safety, Constructions and Safety, Minimizing Accident, Construction Management

\section{INTRODUCTION}

Safety is the state of being SAFE in everywhere, so the rules of safety should be considered, and to implement carefully, the construction industry has long recognized that construction is a high-risk series of activities requiring active safety measures every day. The accident frequency and severity rates in this industry are well above the averages of all other industries, I wish through this research that I could show the reasons of accidents, and the gab of using and implement the safety rules in this sector, then how to solve and to overcome such problems that face the construction sector?

\section{RESEARCH SUMMARY}

The construction industry and construction sector suffering more than other business, because it has one of the highest rates of injuries and deaths among workers and others in the workplace, according to statistics released by the International Labor Organization, while the construction sector includes a small percentage of the very of the total workforce, the safety and professional health science, is the science that devoted to the protection of man and protect him from the risk and prevent the loss of property and lives if it is applied based to the regulations and standards applicable in the KSA. I have this thing struck me in the search for those reasons. The importance of the research, the most important is the availability of prevention means and security on-site, and the extent of compliance with the standards issued by the official authorities in the KSA, and whether these sectors are applying those regulations and laws safety standards? And the extent of follow-up by the official authority for this sector. The research also aims to study the necessary industrial security and safety that should be found in reinforced concrete installations, where the research methodology has a special questionnaire designed, and consistent with the standards of the KSA and international standards, were distributed to a group of companies that deal in the construction and construction sector in the KSA to complete this research, then to compare what they have, and used, and whether it conforms to those specifications? Where the research summarized in the following results, $40 \%$ of the samples, were careful application of safety standards, There are $5 \%$ of had a reservation on it, $12 \%$ of those who apply flatter, $5 \%$ of those who were fearful of filling questionnaire, while $35 \%$ said they applied the regulations to promote their firms ,but in fact incorrect, 3\% said that the reason for the injuries caused by the lack of follow-up and inspection by the official authorities, which requires the development of recommendations that emphasize careful application of safety requirements by the official authority, And not to grant a work permission by the government before they making sure that they apply the safety requirements, and activating the role of official censorship, and ensure the safety of safety devices through a periodic inspection.

\section{INTRODUCTION TO RESEARCH}

In order to achieve the purpose of this research, I designed a special questionnaire on the subject of safety exemplifies where what is supposed to be present in the workplace and means of prevention that contribute to raising the safety and industrial security degree rate to the highest level, based on the regulations and safety standards followed in Saudi Arabia, compared to what is the case they have both in field sites or within constructions, the questionnaire has been distributed in some construction projects distributed in 
different places located in Kingdom of Saudi Arabia, and has been narrowed in the building and construction sector category. The questionnaire has been studied and analyzed well, by the author, in addition to the recommendations and some comments posted in completing the form model of the questionnaire, then to study what came in its provisions, for the purpose of the process of analyzing and study causes.

\subsection{The Main Objectives of the Research and the}

\section{Hypothesis}

The aim of this research is to achieve the main target of raising the safety and industrial security degree rate to the highest level, and then how achieve the ultimate goal for every enterprise to reach "zero incidents" based on the regulations and safety standards followed in Saudi Arabia, that must be met in the reinforced concrete industry, where possible to limit the work injuries, and to keep industrial security equipment's in safe and well conditions, to confirm the validity of these equipment's by checking the state of such equipment's by special official inspectors, in order to protect people and workers in sites from the work injuries, and other construction methods which use in construction at various facilities of reinforced concrete structure, in addition to reach the zero environmental impacts.

\subsection{What is Safety and How Define Safety?}

Safety is the state of being [SAFE] ${ }^{(1)}$ in everywhere, and under healthy conditions, so the rules of safety should be considered, and to be implement carefully, so SAFE is being as follow.

\section{$\mathrm{S}=$ Spot the hazard $\quad \mathrm{A}=$ assess the risk \\ $\mathrm{F}=$ Find a safe way $\quad \mathrm{E}=$ every moment}

It is easy to understand why building construction projects has some dangerous issues, since it involves, large and heavy materials, and equipment's that often work at heights, in holes, underground, and in highly hazardous locations and a thousands of people killed every year, the main cause of the death cases, and injuries in such construction projects are that they are not committed in implementing of the safety rules carefully, or the Ignorance in using such rules, or loss of skills of the workers. Detailed regulations and outlined the tasks and responsibilities that relate to the manipulation safety matters, and civil protection, and some professional people considered safety as profit center in case the safety rules were it well implemented.

\subsection{Hazards Definition}

Nevertheless hazard in a simple definition, is anything that has the potential to cause harm.

\subsection{Identify Who is at Risk?}

"Workers on foot being struck by equipment that is backing up or changing direction; operators being crushed when equipment rolls over while on a slope or when equipment is loaded / unloaded from a flatbed/lowboy truck, operators or mechanics being run over or caught in between when the brakes are not set, equipment is left in gear, wheel chocks are not used, or the equipment and controls are not locked out, and workers on foot or in a trench being crushed by falling equipment loads, backhoe buckets or other moving parts. ${ }^{(2)}$,, , and some other tasks such as scaffolding/ladders, cranes \& critical lifts, materials handling, and so on.

\section{LITERATURE REVIEW}

Based on the International Labor Organization (ILO) statistics on the Safety and health at work topic, and upon to their estimations, that more than $4 \%$ of the Gross Domestic Product (GDP) of the annual worlds is lost as a consequence of occupational accidents and diseases, every 15 seconds, a worker dies from a work-related accident or disease, every 15 seconds, 153 workers have a work-related accident. An estimated 2.3 million people die every year from workrelated accidents and diseases, more than 160 million people suffer from Occupational and work-related diseases, and there are 313 million non-fatal accidents per year. [19], The suffering caused by such accidents and illnesses to workers and their families is incalculable, upon to the literature review offered by "Waleed Al-Ghemlas", titeled as (Safety Management Program), Master Thesis, King Fahd University of Petroleum \& Minerals 2004, [16], and upon to some study cases to safety programs, and other publishing related safety show that a lot of lives are lost and a lot of resources and capabilities are depleted, because of the ignorance of implementations the safety rules [2,12], This is really a very serious alarm knocks in the ears of everyone who is in a position of responsibility to work hard to avoid these problems, or to reduce it to the maximum extent possible

\section{RESEARCH METHODOLOGY}

Based on the results of the questionnaires were designed, which was distributed to a set of institutions and companies, estimated at about 65 companies, and upon to the results of analyzing for the questionnaire, I got the following results that show the strengths and weakness points, then to make the suitable suggestions and recommendations upon to the findings that I got in this search, taking in the consideration the best solutions to avoid the reasons that cause an accidents that occurred because of the abuse of safety rules, and to minimize the accident as much as possible.

The total search sample was 65 sample were distributed to a set of institutions and companies, which equal to $100 \%$, and final result was as follow.

A. 26 samples, equal $40 \%$, who are actually doing the full application of the criteria as stated in the questionnaire.

B. 3 samples, equal 5\%, who had reservations on the credibility of the application of most of what is stated in the questionnaire items.

C. 12 samples, equal $12 \%$, were flatter in application of what is stated in the questionnaire items.

D. 3 samples, equal $5 \%$ afraid to accomplish what came in the credibility of the questionnaire items, fearing for his job and for fear of accountability. 
E. 23 samples, $35 \%$ stressed the application of what came questionnaire, in order of marketing to his company that implements the rules of safety, but in fact they are not fully committed to what is stated in the questionnaire.

F. 2 samples, $3 \%$ who also stressed that the responsibility lies with the official authorities, so as to cause the weakness of supervision and inspection and follow-up of the target sites by them.

Finally, there are some little companies trying to cover up the injury and not disclosed by claiming it as fate and destiny, knowing that the reason may be, in some cases, is the lack of provision and application systems and safety laws as stated in the questionnaire items. The following table and diagram show the ratio of the analyzing results of the research.

\begin{tabular}{|l|l|l|l|l|l|l|}
\hline Comments & A & B & C & D & E & F \\
\hline Search & 40 & 5 & 12 & 5 & 35 & 3 \\
Result & $\%$ & $\%$ & $\%$ & $\%$ & $\%$ & $\%$ \\
\hline
\end{tabular}

Fig (1) - Table Analyzing Results

Represented in the following Chart

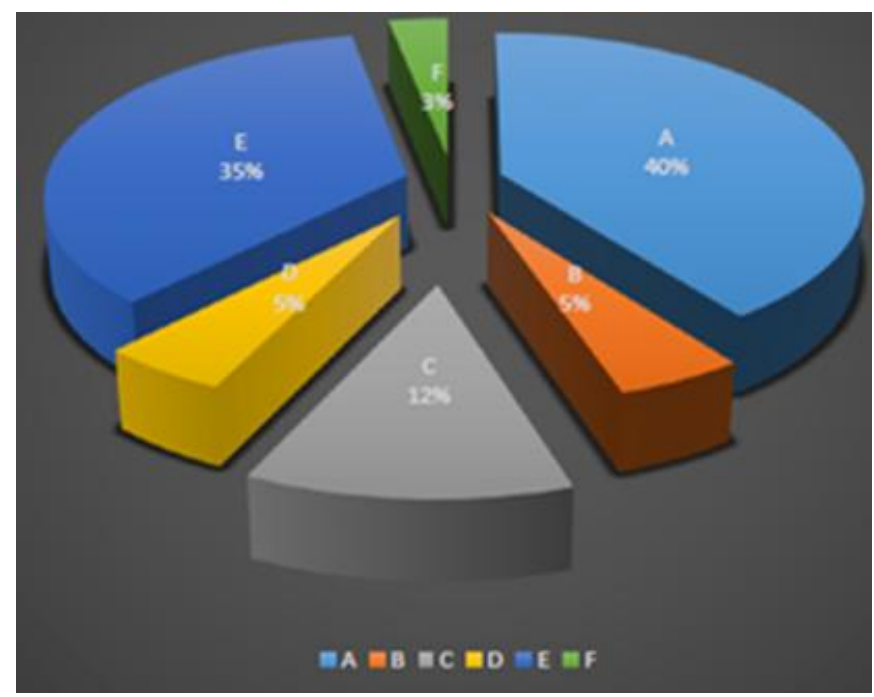

Fig (2) - Research Results

\section{RESULTS \& DESCUSION}

To achieve the goal of safety in order to reduce the problem of accidents the following issues should be followed.

\subsection{Safety Basis}

Must apply the best safety standards for workers in the construction sector and constructors concrete to achieve a safe environment from accidents since this standards consider the main pillar to maintain the safety and security, and the most important criteria are.

1. Create the highest levels of safety and security at construction sites and construction.

2. Verify that all workers in this sector have sufficient information to those standards and the ability to apply and avoid falling into those risks.

\subsection{The Goals of Safety and Security Laws}

The main purpose of the development and application of safety and security laws in the construction sector is to prevent an accidents and injuries that may happen from some workers while working within this sector to achieve this task after open our belief in fate and destiny, the following must be provided.

1. Providing appropriate atmosphere and environment to work in this sector.

2. The continuous work in the development of workers in this sector.

3. Periodic inspection to ensure the quality and validity of the equipment's used in this sector.

4. Implement an action plan and appropriate operating system.

Of course you can't achieve these goals only through the participation of everyone in the responsibilities and application of the provisions of the laws and regulations of safety and security as well as the identification of safety rules in the workplace and how to apply it, and taking into account what is required as well as a special dress and other means appropriate with the nature of the work at the site, which would create a safe and healthy work environment.

\subsection{Classification of Accidents and Injuries in the}

\section{Workplace.}

Where are classified into two types according to their causes.

1. The accidents that may occur at the site as a result of failure to follow safety and security methods or ignorance in their application.

2. The Injuries that may result from the lack of creation of workplace safety and health conditions, The dress, ventilation and lighting, and the cleanliness of the place, and the necessary space for freedom of movement for individuals and others, as well as providing guidance signs on how to evacuate routes in situations of risk, and means of advance warning, in addition to other means and methods that could contribute to the reduction and the prevention of injuries.

\section{RESULTS AND DESCUSSIONS}

Safety as a concept should be translate to practice, by growing awareness of and ability to meet the need and affecting in getting safety. So safety is the state of being certain that adverse effect will not be caused by some agent under defined conditions, any method or process which can minimize unwanted events (accidents) may occur in the site, or concern may be referred to as a method, technique or process of industrial safety. Industrial safety is the science and art of identifying evaluating and controlling workplace hazards. It includes measure to prevent human to unsafe work practices.

It's not connected with the safety of people's life and property as well as the general situation of development and stability. Safety is not a matter of chance; it's something that the employees and their families have a right to expect from 
their employers. There is no such thing as rank when it's comes to safety. It is not "us" and "them" it's partnership."

The important of implementing the rules of safety and realized because every year millions of accident occur which result in their death or in temporary or permanent disablement. Where some of them considered, that accidents because of the fate and destiny and due to the lack of commitment by some construction companies doesn't care enough about health and accident insurance for workers, or because of poor oversight and inspection in the sites.

The workplace accidents costs the state each year billions of Dollars this is an economy cost only, then the human cost in terms of emotional suffering to the partners and families, even workmate of those killed at work. This is immeasurable.

The road toll (casualties in road accidents) is often published but workplace death and injury toll is often overlooked. For many organization health and workplace safety is a compliance cost and they try and get away with what they see as bar minimum. Health and safety are basic desire and instinct. Safety is mainly concerned with minimizing hazards.

Therefore, in order to avoid the unsafe conditions work, and injuries in the work area, you should prepare a safety plan, especially for the equipment's operating in the confined areas, to achieve the optimal production, and workers safety, and the capital. The huge construction companies should have special criteria when they want to choose their own workers, and those workers should be given a physical examination to ensure that they are qualified enough, and to be sure that they can physically operates the equipment's, and they can work well, and they should at least pass the following health requirements.

\section{At least can read, and write.}

2. Proper vision with or without glasses.

3. Ability to distinguish between colors.

4. Adequate Hearing.

5. No physical defects to impair performance.

6. No proneness seizures or loss of physical control.

7. Sufficient strength, endurance, agility, coordination, and reaction to meet equipment demand.

All employees and workers, who operate the construction equipment's, should get enough training by the site engineer through special training program offered when they need.

\section{CONCLUSION\& RECOMMENDATIONS}

The conclusions that I got through this research are so much benefits will be obtained, such as, will keep skilled workers, humanitarianism, keep of morale, and keep productions, reduce the direct cost of insurance and accidents, keep production on time, keep management and worker time for investigation, and finally keep equipment's.
And the following recommendations and issues should be keep in mind in order to reduce safety problems, and reduce the rate of accidents.

1. Confirm what came in the regulations and safety regulations, and professional health issued by official institutions such as municipalities and civil defense department and the Saudi standard specifications.

2. Not to grant any licenses to practice the profession before making sure health and safety of the place and it contains full safety requirements professional.

3. Activating the role of official censorship in control periodically and randomly.

4. Subjecting the devices and equipment's that used in the construction sector to the periodic check, and to make sure the safety of the operating.

5. Full insurance that should be made upon to the requirements of the official authorities. And then to.

6. Make sure not to prejudice or influence on the environment in the working area.

\section{ACKNOWLEDGMENTS}

First of all I would like to express my great thanks to God Almighty for helping me to finish this humbly research, and this is my pleasure to express my special thanks to "Taif University Administration", for their full support to the scientific research in the university, I'm also grateful to my family, all engineers and engineering companies who gave me their hands to help, for granting and supporting me by the data that I need to complete the research. Finally I'm very much appreciate the encouragement and friendly assistance given to me from all colleagues.

\section{REFERENCES}

[1] Anupama Prashar, \& Pratibha Garg, Industrial Safety and Environment, S.K.Kataria \&Sons 2012.

[2] DOUGLAS D. GRANSBERG CALIN M. POPESCU RICHARD C. RYAN Construction Equipment Management for Engineers, Estimators, and Owners, , Taylor \& Francis Group, FL 33487-2742, USA, 2006.

[3] OSHA Standards for the Construction Industry Part 1926 - Safety and Health Regulations for Construction.

[4] Feng, Y. (2013). "Effect of safety investments on safety performance of building projects." Safety Science, 59, 2845. Online publication date: $1-\mathrm{Nov}-2013$.

[5] Hinze, J., Hallowell, M., and Baud, K. (2013). "Construction-Safety Best Practices and Relationships to Safety Performance." Journal of Construction Engineering and Management, 139(10), online publication date: 1-Oct2013.

[6] Hallowell, M., Hinze, J., Baud, K., and Wehle, A. (2013). "Proactive Construction Safety Control: Measuring, Monitoring, and Responding to Safety Leading Indicators." Journal of Construction Engineering and Management, 139(10) online publication date: 1-Oct-2013.

[7] The Management of Health and Safety in Civil Engineering, Institution of Civil Engineers (June 1995).

[8] Deutsche Berufsgenossen schaft der Bauwirtschaft (2010). Arbeitssicherheit und Gesundheitsschutz am Bau 
[9] Österreichisches Bundesministerium für Wirtschaft und Arbeit (1999). Bau arbeit enkoordinations gesetz (Bauch)

[10] Kern et al. (2005). Einführung in den Arbeits schutz: für Studium und Betriebspraxis

[11] Forschungs projektzu Arbeits- und Schutzgerüsten im Bauwesen (1998). Technische Universität Graz

[12] M.R.Sharma, Fundamentals of Construction Planning \& Management, S.K.Kataria \& Sons, November 2012.

[13] Charles Lessard and Joseph Project Management for Engineering Design, Lessard, United States of America, by Morgan \& Claypool, 2007.

[14] Laboratory Design Guide, Brian Griffin, B Arch (Syd) FRAIA MDIA ARIBA by Integra Software Services Pvt. Ltd, Pondicherry, India Third edition 2005.

[15] General Directorate of Civil Defense, Ministry of the Interior, Saudi Arabia.

[16] Waleed Al-Ghemlas, Master of Engineering Report, Safety Management Program, King Fahd University of Petroleum \& Minerals, 2004

[17] General Organization for Vocational Education and Training - Saudi Arabia - General Administration to design and develop curricula

[18] Saudi Arabia standard organization (SASO) and Saudi Arabia safety code national committee.

[19] http://www.ilo.org/global/topics/safety-and-health-atwork/lang--en/index.htm

[20] Zoman Mohammed Al-Hajri \& Partner, Loss Prevention and Construction Safety Plan, Alkhobar KSA, 2015 